\title{
Engineering Publics: The Different Modes of Civic Technoscience
}

\author{
Sascha Dickel \\ Institute of Sociology, Johannes Gutenberg University Mainz, Germany/dickel@uni-mainz.de
}

Christoph Schneider

independent researcher and consultant, Germany

Carolin Thiem

VDI/VDE Innovation+Technik GmbH, Germany

Klara-Aylin Wenten

Friedrich Schiedel Chair for the Sociology of Science, TUM, Germany

\begin{abstract}
Amongst the many modes of citizen science in the past years, civic technoscience has emerged. Whilst 'science' tries to explain the world, 'technoscience' tries to construct technological worlds. Whereas citizen science involves publics to contribute to data gathering and interpretation, civic technoscience involves publics in technological world making. By creating prototypes for engineering publics, civic technoscience expands the regime of technoscience into society. The article analyses three different cases of civic technoscience: a FabLab, a for-profit makerspace and a civic hackathon. These cases represent three approaches to civic technoscience: an emancipatory, an entrepreneurial and a science communication approach. Our ethnographic analysis reveals that these approaches need to be considered as ideal types: All our cases were shaped by an entanglement of emancipatory, entrepreneurial and science communication aspirations and practices.
\end{abstract}

Keywords: citizen science, technoscience, maker movement

\section{Introduction}

What happens when technoscientific practices enter the public sphere? How is technoscience performed as a public matter and how are publics themselves constituted by taking part in technological world-making? What kind of messy and unexpected technosocial relations are forged when technoscience becomes a mode of citizen science?

In this paper, we discuss and analyse different forms of 'civic technoscience' (Wylie et al., 2014) to 
understand new practices of 'material participation' (Marres, 2012) in the public sphere in which citizens collaborate to explore, invent, produce and use technologies in a public manner. During the past decade, people with different societal backgrounds and occupations have been increasingly invited to join the technoscientific enterprise: to experiment with (digital) technology, to develop new technological solutions for society's problems and to position themselves as engineering and innovative subjects.

In the first section of our paper, we discuss the distinction between technoscience and citizen science. Our second section presents three case studies that demonstrate different modes of civic technoscience situated in different organizational contexts. With these cases, we demonstrate that civic technoscience is already diverse and assembles different publics. We conclude with reflections on the role of civic technoscience in contemporary society.

\section{Citizen Science, technoscience civic technoscience}

Contemporary academic discourses on science and technology paint two very different pictures: On the one hand, we seem to have entered an 'age of technoscience' (Nordmann, 2011), dominated by emerging technologies and constructed in expensive laboratories that are inaccessible to the public. On the other hand, we seem to have entered an age of citizen science, shaped by novel forms of public participation in the scientific enterprise or varyingly as a 'democratization of innovation' (Hippel, 2005). We argue that technoscience as a contemporary mode of knowledge production is also becoming an increasingly public matter. We discuss this expansion of the technoscientific enterprise into the public sphere, thereby constituting new technosocial publics.

\section{Citizen science: Extending the scientific enterprise}

Within the "post-war social contract" (Jasanoff, 2003: 227) between science and the public, scientists were regarded as a distinctive truth class, sharply separated from ordinary citizens. Science communication was therefore informed by the deficit model, which suggested that the public needed to be educated about science by certified scientific experts. The divide between (scientific) experts and (non-scientific) lay people appeared to be a social and an epistemic one. The noncertified expertise of people outside of scientific institutions was largely neglected by professional scientists (Collins and Evans, 2002).

With the emergence of citizen science, however, public participation is expected to (re-)enter the heart of scientific knowledge production: scientific research (Finke, 2014). The term citizen science refers to projects that involve citizens not primarily in the mode of deliberative governance but as contributors to research, often enabled by digital infrastructures and mobile devices. In citizen science, project participants explore their environment, measure the noise pollution of their cities and reconstruct local histories.

Contemporary science policy discourses present citizen science as a tool of knowledge production and a tool to increase scientific literacy. They legitimize citizen science as a mode of doing science and as a mode of science communication (Bonney et al., 2009; Serrano Sanz et al., 2014). According to the narratives of citizen science, scientific research may again become a public matter. While the scientific enterprise in modernity was inherently linked to the scientific profession of certified experts, the socio-epistemic regime of citizen science aims to open research to non-professionals: "What was once a novel idealay people engaging in the scientific enterpriseis becoming mainstream" (Bonney et al., 2016: 14).

Citizen science is interesting for STS because it attempts to both weaken and strengthen science as a modern institution. Citizen science questions the 'jurisdictional claim' (Abbott, 2007) of science as a profession by allowing public participation in research. At the same time, it aims to extend the scientific enterprise of knowledge production into the public sphere. Empirical inquiries show, however, that citizen science at the level of specific projects is much more complex than the popular discourse on citizen science implies. Citizen science projects are very heterogeneous, they do not involve the public in a general sense and they assume different levels of expertise as conditions for public contribution. They are 
organized for different reasons and by different means, involving different forms of division of labor and hierarchy (Dickel and Franzen, 2016).

\section{Technoscience: creating technology}

In order to understand civic technoscience as a special mode of citizen science we need to first distinguish between science and technoscience. In recent years, some authors have begun to analyse the epistemic objects, goals and institutional foundations of technoscience as a specific and increasingly important mode of knowledge production in contemporary society - one different from science. This distinction is also an important way of differentiating citizen science from civic technoscience.

A rather general notion of 'technoscience', coined by Bruno Latour (1987: 174), has gained much prominence in STS. In Latour's (1987) view, science and technology have always been technoscience. They assemble social, material, technological and intellectual aspects to create and circulate knowledge. Science, however, 'purified' its messy embeddedness in sociomaterial networks through claiming for pure and universal knowledge. Following Latour, our contemporary world starts to question this work of purification. This questioning allows technoscientific innovations to become explicit activities formerly separated by notions of 'science' and 'technology' (Latour, 1993).

Nordmann (2011) proposes a more distinctive view of technoscience that we deem important to follow if we are to distinguish different modes of science and citizen science. According to Nordmann, there is an increasing dominance of a specific regime of technoscience within modern science and its relations to society. In Nordmann's theory, the term technoscience describes contemporary strategies of knowledge production, legitimizations and relations to the natural and social world that focus on the creation of novel technological capabilities. These strategies differ from the strategies and aims of 'science' that focuses on the creation of better theories. Whereas the aspiration of the scientific enterprise was the discovery of truths, the aspiration of technoscience is the production of technological innovations. The contemporary notion of technoscience gained prominence within emerging fields such as nanotechnology, biotechnology, computer- and neurosciences. Common features of these fields are rationalities of engineering, which are translated into other academic fields, social contexts and societies. A prototypical example of this is synthetic biology, which tries to apply an engineering approach to biology in order to design novel biological systems and, in turn, to radically alter societal relations to nature. However, technoscientific rationalities also increasingly enter everyday life, politics and the public sphere. Part of the regime of technoscience is the existence of diverse 'sociotechnical imaginaries' (Jasanoff and Kim, 2009) that entangle technoscience with societal problems (Grunwald, 2014; Nordmann, 2016). Technosciences promise to reconfigure the world at micro and macro levels, to transform whole societies into novel post-human 'megamachineries' (Mumford, 1970) and to reengineer life, matter and information at the level of genes, atoms and bits (Roco and Bainbridge, 2003). From the perspective of technoscience, everything can and should be designed and transformed through technological inventions and interventions. This technoscientific imperative is being constructed and enacted through various futuristic discourses that are central to how technoscience is legitimated and entangled with publics and politics. Thus, much of the public appeal of mainstream technoscience is based on grand promises about how new technical capabilities might turn into innovations and redesign society (Dickel and Schrape, 2017; Sand and Schneider, 2017).

\section{Civic technoscience: Extending the techno- scientific enterprise}

It might appear as if technoscience and citizen science refer to distinct and mutually exclusive socioepistemic regimes: While institutionalized science reconfigures itself (partly) as (explicit) technoscience, the 'traditional' scientific enterprise is revitalized and extended through lay participation in the mode of citizen science. This simplified view also corresponds to the self-descriptions of some citizen science protagonists. Finke, for example, conceives of citizen science as a way of preserving the scientific enterprise in the face of an institutional science system that, due to recent 
economic and political pressures, is increasingly more interested in the production of innovation than in the production of truth (Finke, 2014). Both regimes imply very different roles for the public: While the scientific enterprise of modernity imagines the public as citizens in need of education (about scientific truths), technoscience imagines the public as users of technological innovations. The public's role is restricted to either embrace the imaginaries of technoscience or to engage in critical discourses (Nordmann and Schwarz, 2010; Gaskell et al., 2005).

To transcend such dichotomies, Wylie and colleagues offer the term 'civic technoscience' by which they designate sociomaterial settings and strategies that "sustain a civic research space external to the academy and where non-academics can credibly question the state of things" (Wylie et al., 2014: 118). Although the authors focus on specific technoscientific practices, this is not reflected in their definition. Following Nordmann's argument for a strong characterization of technoscience, we restrict the notion of civic technoscience to civic research with a focus on the creation and exploration of technologies. This resembles a growing literature on a 'democratization of innovation' (Hippel, 2005). However, the key difference is one of framing and perspective. The framing of democratized innovation is based upon an economic logic of technological development. The framing of civic technoscience highlights the public and civic logics that are becoming visible if technologies are not simply seen as products and the involved people are not simply seen as users or consumers.

Several trends and transformations of contemporary societies have contributed to the emergence of civic technoscience. The public sphere has been massively transformed through the Internet: Through various platforms, diverse publics have come into existence (Castells, 2002). 'Openness,' 'transparency' and 'collaboration' have become important political terms under the condition of such digitised publics (Tkacz, 2015). In contemporary societies, many if not most futures and transformations are being considered as consequences of (digital) technological innovations (Urry, 2016). As a paradoxical effect of technoscientific imaginaries, many novel technologies have become public issues which contributed to the delegitimization of certain forms of certified expertise. All kinds of public engagements, policies and publics are formed and transformed into novel technosocial arrangements that are being forged into existence with the purpose of involving all of society in technoscientific matters (Lösch and Schneider, 2016; Nordmann, 2016). The recent proliferation of 'material participation' (Marres, 2012) must also be considered as a proliferation of technical objects. Technological artefacts in qualitative variety and quantitative scale are acquirable and accessible on almost global scale. In particular, digital objects are increasingly being perceived and desired as malleable, connectable and unfolding things (Knorr-Cetina, 1997). Open source software development combines these transformations and became an example for many aspirations in civic technoscience. In open source projects, online communities develop technical objects and publish documentation, blueprints and design files online to foster the sharing of technical knowledge.

Civic technoscience enables collective public experimentations with (often digital and open) technologies, which includes the sharing of technological knowledge and the aspiration to develop technological solutions to society's problems with and by publics. In order to investigate how the tensions between publics and institutions - which became already apparent in citizen science - also shape and affect civic technoscience, we will now focus on specific local publics. How are both civic technoscience and its publics produced? What are the similarities and differences of specific instances of technoscientific participation?

\section{Civic technoscience in practice}

The following section presents three variants of civic technoscience. The selection of cases rests on a comparison of dissimilar instances of civic technoscience in Germany. We are starting with a case reflecting an emancipatory approach to technoscience: a grassroots FabLab that aims to facilitate civil society engagement with digital fabrication. We then introduce a for-profit maker- 
space that is part of an entrepreneurship center of a leading technical university, demonstrating an entrepreneurial approach to public involvement. We close our presentation of cases with the analysis of a civic hackathon, carried out by on organization for public understanding of science and technology, reflecting a science communication approach to civic technoscience.

The analysis is the result of extensive ethnographic work. We took part in the typical activities of the respective fields and conducted interviews with a variety of actors. In all cases, a distinction between a core group of 'organizers' and 'participants' was visible, thus we talked to both groups. We also discussed our findings with the actors in the respective fields. Before and during our participant observations, we examined documents like websites and flyers to understand self-descriptions and self-displays. Attention was also given to the material infrastructures as well as to the geographical and institutional environment in which the activities took place. In order to understand the similarities and differences of the cases, we analysed each field according to the following dimensions:

a) Governance mechanisms: How is participation enabled and organized? What kinds of actors are involved? What strategies are deployed to enable public engagement?

b) Dynamics of inclusion and exclusion: Who should, according to the self-descriptions of the field, be included in the activities? How is inclusion of publics facilitated? What groups are excluded (be it by means of discourse or practice)?

c) Spatiality and temporality of engagement: Where does participation take place? What is the role of local infrastructures? Do the activities result in a long-term engagement of publics in civic technoscience (be it inside or outside of the boundaries of the respective field)?

d) (Blurring of) boundaries between experts and lay persons: Does the field problematize established distinctions of experts and lay persons? Are some boundaries blurred and/or do new ones emerge? Who counts as an expert in the first place? Is the jurisdictional claim of certified experts challenged?

\section{A Grassroots FabLab}

Grassroots organizations have proven to be particularly relevant to transform scientific practices (Jalbert, 2016). Thus, our first case is a 'grassroots' FabLab in Germany that has been run by voluntary members since 2014. FabLabs, short for 'fabrication laboratories,' have become particularly prominent during the last decade as a novel form of workshop that is accessible to publics and which is mainly based around machines and processes of 'digital fabrication.' FabLabs define themselves through working with at least a set of computer numerically controlled (CNC) machines, such as 3D printers, laser cutters or milling machines, although many FabLabs offer other tools as well. The concept for FabLabs was initially conceived at the Media Center of the Massachusetts Institute for Technology (MIT) around the year 2000, where the technoscientific aspirations to control matter digitally, together with a form of science funding that fostered engagement with society, created the idea of making CNC machines publicly accessible. This move was particularly inspired by an emerging imaginary of highly capable digital machines available to individuals. This led the researchers to speculate about a "digital fabrication revolution" that would enable everyone to make anything anywhere, just like the personal computer enabled the decentralised production of immaterial goods (Gershenfeld, 2012).

Although in the first years, the initial FabLabs had close ties to MIT and thus to institutionalized and elitist technoscience, this changed dramatically around 2010. Troxler (2014) describes how, in the Netherlands networks of researchers, artists and tinkerers wanted to start FabLabs without formal relationships to MIT and also on a more affordable basis. The first 'grassroots' FabLab was thus established by a community of artists and social activists with a budget of $€ 5000$ in a town in the Netherlands (Troxler, 2014). As of 2018, there are around 1300 FabLabs across the globe, variously run by a hosting organization, as a company or as a member-based organization (Fablabs.io, 2018). Formal ties to MIT are no longer necessary to start a FabLab. It is rather expected that each FabLab hosts a similar set of machines and subscribes to particular guidelines, the 'Fab Charter.' Already at MIT but increasingly so with 
the spread of grassroots FabLabs, a form of public and participatory expertise has been enacted by these workshops. Their governance is shaped by the cultural ethos of making digital fabrication accessible to individuals.

In 2013, a group of citizens of a German city participated in a project to establish a grassroots FabLab. In early 2014, the FabLab opened its doors and, at the time of writing, became a memberbased non-profit organization with about 150 members who pool their resources-what is called a 'Verein' in Germany (essentially a club or association). In a room of around $80 \mathrm{~m}^{2}$, the organization offers its members (and once a month also non-members) access to several 3D printers, a laser cutter, a CNC mill, electronics and common tools. Members pay a fee of around $€ 20$ a month and elected a board that manages the association. Mostly, the lab is used by its members to pursue individual 'hacking,' 'making' or other do-it-yourself (DIY) projects such as furniture, lighting, small robots and, particularly important to many of its members, building and improving CNC machines, especially 3D printers. Most of the members are hobbyists and technology enthusiasts with a professional background in technology. However, most also see the FabLabs as separate from their work and as a space for leisure and civic involvement. On an informal level, inclusion and exclusion is largely based on these cultural and habitual aspects of the members who voluntarily choose to associate with like-minded others.

In addition to being an organization for interested individuals, the FabLab offers special events and outreach courses, e.g. to school kids, that convey technical skills and enable people to explore digital fabrication technologies. The education about and the promotion of digital fabrication is one central area and an important goal for the organization. Similar to other civil society organizations that are member-based, e.g. sports associations, the FabLab hosts facilities for particular (technical) practices and provides teaching and a space to socialize. Thus, while the FabLab typically reaches out to people that are interested in technology and tinkering, it addresses a wider public through its special events. All these activities are based on an imaginary of the desirability of digital fabrica- tion and its further dissemination. However, most of the digital fabrication processes in the lab are rather difficult to operate and mastering them requires a lot of time. The FabLab thus assembles experts in digital fabrication at special times, such as in courses or public events, who try to share their knowledge with others. Therefore, while the core members (who typically have self-trained or professional technical expertise in digital fabrication) participate on a regular basis, there are more spontaneous and irregular forms of participation by other groups. Expertise is often explicitly questioned and the aim of making technologies accessible to others gives meaning to the educational aspirations of the organization.

In tight entanglement with the spread of FabLabs beginning around 2005, the 'maker movement' emerged and began to grasp the imaginations of hackers, DIY enthusiasts, the media and even policy makers. Considering the spatial and infrastructural organization of this and other FabLabs, one needs to see these organizations in relation to the global assemblage of the maker movement. This global network has enabled local labs and practices through networked and digitized forms of participation in technical knowledge as well as social imaginaries of open source technologies. The term 'maker' was first used by a publisher for computer and software literature in order to reach out to a more diverse audience of people interested in tinkering with technology and to avoid the negative connotations that sometimes accompany the term 'hacker.' The respective magazine and trade fairs that included all kinds of DIY projects quickly helped to turn 'making' into an umbrella term for various DIY practices that increasingly used the Internet to coordinate and share ideas. In addition to creating an imaginary of decentralised and user-led innovations through makers, within this movement organizational settings emerged. 'Hackerspaces' - mainly concerned with software and computers since the 1990s - started to include other technologies. Spaces that sought to emphasize their association to the maker movement labelled themselves 'makerspaces'. The maker movement turned making into a public issue and it also helped to build and legitimize FabLabs - and as we show below, other organiza- 
tions as well. FabLabs can be viewed as a specific subset of makerspaces specially aimed at making digital fabrication public.

The publics of open source projects have been particularly important for the technoscientific practices within the investigated FabLab. Again, entangled with the rise of the maker movement and FabLabs, there has been a spread and increasing diversity of open source projects aiming at developing technology. Significantly, in 2004, the open source 3D printing project 'RepRap' started to publish building instructions for such machines in the public domain. By now, the project has laid the foundation for hundreds of relatively inexpensive 3D printer designs. It also helped to create a 3D printing hype by having made visible and graspable the idea of individually usable and affordable 3D printers for 'everyone.' There are many more of those projects where Internet-coordinated collectives design technologies and publish explicit knowledge under public licenses, e.g. creative commons licenses, to share technical knowledge. These have been highly relevant to the existence of the investigated FabLab. On the one hand, most of the core members of the lab became interested in FabLabs and gained expertise in digital fabrication through their engagement with open source projects - mainly 3D printing. On the other hand, much of the digital fabrication infrastructure in the FabLab is based on open source designs and was partly built by the members themselves. This dramatically lowered the cost of this technical infrastructure as compared to similar industrially applied machines. We might say that these open source projects assemble individuals who foster and learn a form of technical expertise with an ambition to publicize and share knowledge.

Taken together, civic technoscience in the FabLab has several dimensions. There is the member-based organization that aims to facilitate experimentation with digital fabrication machines. The people running this institution regard it primarily as a civil society organization, which tries to empower citizens. These citizens are imagined as actors who are willing to become empowered through digital fabrication and invest their time to do so - spreading digital fabrication is seen as their civic duty. Furthermore, the FabLab assembles wider publics that centre around digital technologies and DIY practices and that have contributed to turning making, open source, and digital fabrication into public issues and emancipatory paths to reconfigure technoscience (Dickel and Schrape, 2017; Schneider, 2018).

\section{A makerspace at a university's entrepre- neurship centre}

The second case presents results from ethnographic fieldwork that has been conducted at a makerspace at a German university. We show that, although this makerspace seeks to attract an unspecific, heterogeneous public, its organizational structure and socio-technological setting nevertheless puts limitations on the participation and engagement of these same publics.

Makerspaces are declared to be 'open to everyone,' allowing each individual to gain experience with professional machine tools, materials and practices of design and engineering. This turn towards collective spaces of fabrication is often seen as an act of empowerment, rendering those actors more integrated and proactive that have so far been excluded from engineering practices.

The makerspace this chapter draws on is closely affiliated with a university's entrepreneurship center. While some makerspaces - like the FabLab described above - are collectively governed and organized by their users (bottom-up), the makerspace here reveals more hierarchical structures (top-down). The team comprises a general manager surrounded by a core team that runs the workshop, its infrastructures and events, develops marketing strategies and builds collaborations with companies or public institutions. The makerspace has additional crewmembers and trainers who primarily work in the workshop itself, maintaining the machines and storage rooms, as well as teaching and providing the users with technical knowhow and skills. Based on interviews we conducted during our fieldwork, the makerspace team regards itself as a business and service provider (Interview, Manager, January 2016). Unlike other shared workshops, the makerspace does not rely on donations. Rather, it has developed an economically oriented business strategy that attempts to commercialize working spaces for companies, firms, smaller start-ups and 
private users in order to let them build, design and prototype their project ideas. The workshop is equipped with professional and high-tech machine tools that are often also utilized in industrial manufacturing. Their facilities range from 3D printers, laser cutters and industrial sewing machines to water jet cutters, metal or wood band saws and other CNC machines.

In light of their close cooperation with larger (industrial) companies or events like 'makeathons', the makerspace's main goal in terms of public engagement is to extend its services to as many different groups and actors as possible. Although it regards itself as a service provider, the makerspace does not work as a 'manufactory' for customers. Rather, at the core of their service stands the provision of the workshop itself, the maintenance of the machines and introductory courses. In the following, we will describe how specific governance mechanisms organize and engage with the public by explicitly focusing on the makerspace's courses, the use of the machines and their user groups. We also show how the dynamics of inclusion and exclusion of this present case of civic technoscience challenge the potential of integrating a wide and heterogeneous public that the makerspace has sought to address.

To begin with, the makerspace works on a membership basis. Companies, start-ups, student groups or private users have to apply for a membership that permits them to enter the workshop. In order to use the machines and tools, members have to attend introductory courses that require paying additional fees. In contrast to 'bottom-up' makerspaces, this case offers specialized and professionalized courses being run by trained crewmembers who introduce and explain the respective machines. The actors involved thus seem to regard their contribution to a wide public engagement in the act of teaching and distributing technical knowledge amongst every member. The courses usually run for up to two to three hours, where participants learn specific technical skills, for instance, how to build a bottle opener out of metal. During the course, participants are equipped with material, instruction papers and safety glasses. All these conditions aim to develop and improve the user's skills and crafting abilities.
Only after having attended the course (at least once), members are permitted to autonomously use the machines for their individual purposes.

Participation in the makerspace is thus initially organized and guaranteed by the courses and the possibility to apply the gained knowledge in order to autonomously use the machines. The courses are meant to address a heterogeneous, unspecific public by claiming to invite everyone to work and take part in innovation and engineering processes. Introductory courses and instructions inform those participants who have not yet acquired concrete practical experience about how to craft and construct objects. Moreover, they seek to create an atmosphere that puts every member on the same level of expertise and knowledge. Accordingly, the makerspace seems to attract and include a wide, heterogeneous public, consisting of professional engineers, hobby-tinkerers and actors without any experience. All of them play an important role in the (co-)production of technological artefacts, as well as in the process of generating innovation and knowledge about it. Consequently, the public in this field of civic technoscience cannot only be seen as one becoming educated (the usual public of science) or one using or deliberating technological innovation (the usual public of technoscience), rather it operates as one that is itself active in engineering processes.

However, while the public of makerspaces is sought to be diverse, our research revealed that this is not always the case. Trainers with expertise and skills, as well as the business model (which rests on membership fees) and the socio-material setting (that includes highly professional and expensive machine tools) already pre-define the kinds of users that can access the investigated space. During our ethnographic study, we experienced particular dynamics of exclusion when talking about the function of 3D printers:

I walk around the workshop and look at all the different machines in the 3D printing area. One of the bigger machines is currently working and I wonder what it is exactly printing. I ask a crewmember who is just about to check the machine. I feel a bit clumsy and illiterate when asking about what it is printing. She turns around and replies in an astonished manner: "You don't 
know how this machine works?!" Now I feel even more unsettled since I thought I articulated my question clearly. I stumble “No, I mean, yes... But I wanted to know what the 3D printer actually creates?" She talks about her project and mentions a chair that she likes to produce. I realize how she still loses interest in keeping the conversation going because after a few sentences, she turns around and seems to concentrate on the screen. (Field notes)

This extract from our ethnographic field notes demonstrates how crewmembers that are familiar with the respective machines seem to expect a certain level of expertise and knowledge from the user beforehand. In this particular situation, the ethnographer had little knowledge about 3D printers and was quickly viewed and approached as a non-expert. While the makerspace is claimed to be a place for everyone without any expertise, we can yet see how social expectations entangled with the professional quality of the machines actually construct a more specific public, namely one, which already possesses technical expertise.

This case has moreover revealed that it is primarily those actors with a concrete idea and project plan that appeared to benefit most from the workshop. During the ethnographic study, our researcher attended courses at machine tools that, for instance, taught her how to draft and produce a bottle opener. We observed that for some participants it was difficult to know directly how to craft construction plans that were required in order to further proceed within the course. A mere introduction into the type and use of a machine did not immediately help since the courses demanded additional knowledge and expertise - for instance, when choosing the right material or crafting out construction plans and drawings. As follows, in addition to the dynamics of exclusion that were enacted by the actors' expectations, the structure and pre-requirements of the courses similarly contribute to shaping and pre-defining a more specific public. Moreover, the types of projects to be drafted directly in the workshop were already constrained (if not hindered) owing to membership fees and the concurrent necessity of pre-preparation. Consequently, this form of civic technoscience can only address and integrate those publics that already possess technical familiarity and expertise, an interest in technology and crafting, as well as concrete project plans.

It is therefore not surprising that during the fieldwork, the makerspace was mainly used by start-ups, industrial companies and professionals who work in the field of engineering or innovation management. The users who were less familiar with crafting, tinkering or manufacturing were, in turn, considerably fewer. Moreover, according to a private user, "there are so many members from the makerspace walking around. Like staff-members [...]. I haven't seen that many students so far but also not really old people" (Interview, User, May 2016). This might seem to be paradoxical, considering the fact that the makerspace is located right at the university campus, and one might expect that a great number of students would use the makerspace facilities. Nonetheless, due to factors like membership fees, pre-existent knowledge or general interest, the makerspace failed to equally integrate younger user groups like students. This, again, underpins our conclusion that the public attracted here seems to be a rather exclusive one, primarily involving those actors who possess specific forms of expertise and business interests. As our ethnography has consequently shown, in most of the cases the involved actors running the makerspace were not aware of these dynamics. This relates to the entrepreneurial approach of the makerspace, which preconfigures the kinds of publics it aimed to attract.

\section{A Civic Hackathon}

In our last case study, we analyse a civic hackathon focused on urban innovation and sustainability. The civic hackathon (Schrock, 2016) was conducted in a major German city in 2015 and lasted two days. Compared to the cases we have already presented, this civic hackathon was not organized by a non-profit organization or a company but by an organization for public understanding of science and technology with close ties to the German Federal Ministry of Science and Education (BMBF). It usually organizes discussions and exhibitions dealing with science and technology. In this special case, the institution collaborated with a non-profit organization (NPO) that advocates open knowledge and open data and promotes 
and supports (digital) civil rights. Therefore, one focus of the hackathon was on topics like freedom of information and open science. After the event, the groups were given the possibility to develop their ideas at so-called 'Citizen Science Labs' (regular meetings at the already existing open science organization's labs).

During the last decade, it became popular to arrange civic hackathons for enhancing science policy and science communication 'off the beaten path'. Hence, when proposing this particular event to the ministry, both organizations used the rhetoric of hacking and making to describe their approach to socio-technical innovation. Adapting this rather unconventional event was a challenge for the institution of science communication. However, it was also a possibility not only to discuss technoscientific issues in public but also to activate citizens to become participants in the generation of technoscientific innovations themselves. The collaboration with the open science NPO enabled the public engagement organization to interact with citizens in a completely new way that broke with their own routines (Interview, Organizer 1, July 2015). The hackathon assembled a special public and we will show why, at the end, this public was more exclusive than the organizers had originally planned and sought.

Both organizations aimed to generate a public to create innovations for a more open and sustainable city within two days. The event started on a website where interested citizens had to sign up for the respective hackathon in their city and chose one participant category (programmer, designer, city enthusiast or scientist). These categories reveal that the initially addressed public was imagined to consist of certified scientific experts as well as citizens with expertise in hacking (programmers) and making (designers) - but also inexperienced people who were motivated to participate because of a desire to improve urban environments (city enthusiasts). Only citizens with access to the Internet were able to subscribe to the event - so this registration by itself constituted a first moment of exclusion. During the registration process, the participants were already encouraged to formulate and discuss ideas on how to improve their city and how to publish them on a digital platform. Examples of the discussed ideas were rooftop gardens or open bicycle maps. Later on, these ideas served as 'icebreakers' during the pitching session, an important part of the civic hackathon, and at the same time as the visualization of differences in hackathon experience.

The event itself took place at a biotech start-up located in a backyard in an alternative and multicultural district of the city. The space was decorated with vertically hanging plants and hosted a large coffee bar, all of which is in line with the typical gathering spaces of the creative class in the respective city. Still, the start-up was not able to provide the 'right equipment' for the hackathon such that organizers had to arrange the necessary technological apparatuses. It is important to mention that the 'right equipment' was defined by the organizers themselves. Using the existing infrastructure at the individual locations, they created a hacking place at the biotech start-up with Arduino kits and modelling clay so that the citizens could experiment without instructions. The provided 3D printer as well as the sensor set was introduced and curated by experts who answered questions and provided practical help for laypersons. The participating citizens were encouraged to access the technology, to print prototypes or to work with sensors.

The day started with the participant registration in the morning where everyone received a coloured sticker that marked his or her particular group affiliation. Red stickers, for example, marked the group 'scientists.' After welcoming the participants, the theme of the event was introduced by 'Lightning Talks' where speakers discussed different topics such as classical citizen science, but without building the connection to the specifics of civic technoscience. During the following pitching session, the participants were asked to communicate their ideas for improving the city through short presentations in order to attract possible collaborators. We could observe that some participants were quite experienced in these formats, especially participants belonging to the hacker community. They had the special expertise about how to pitch properly, so that people became interested in working on their ideas. Other participants had problems defining their goals or communicating their ideas to the audience. During lunch break, the participants 
were asked to form hacking groups that were expected to work together for the following two days. Not everybody was able to find a group, or in other words, they did not have the right expertise to orient themselves in the informal procedure of a civic hackathon. Therefore, the process of pitching and group finding can be seen as the biggest moment of exclusion. The organizers acknowledged this problem. Hence, they moderated the group finding process in the following year and helped people to connect to other participants.

After building groups (or not), the hacking started after the lunch break. Working on their chosen projects in small groups, some group members programmed while others experimented with the sensor sets, and a few also used the $3 \mathrm{D}$ printer to try to create models - always supported by a 3D printing expert. On day two, the number of participants was scaled down, meaning that, for example, two groups only had one member left. Following a second working session with the remaining groups, the groups presented their results and a jury selected the three best projects. The winners each received a coupon for hardware acquisition (e.g. sensor technology, Arduino kits, etc.) worth $€ 500$. Despite having been originally announced by the organizers, none of the invited representatives from the city showed up. Six digital and non-digital prototypes were praised as solutions for urban problems like the lack of cycle paths and global problems like air pollution.

However, the hope that the hackathon might serve as a starting point for a long-term engagement activity did not work out. Therefore, the officially communicated goal of this event was not achieved. Nevertheless, some citizens were able to experiment with sensor kits or used 3D printers for the first time in their lives and reflected upon technological innovations for sustainability. Hence, a few unexperienced participants gained some technological knowledge associated with hacker or maker communities (however, scientific knowledge - e.g. comparable to an academic engineering curriculum - had not been transferred). All in all, we observed that it was generally helpful to already possess experience with hackathons in order to endure the two days of insecurity around the idea-finding- and realizing-process.
Contrary to the aspirations of the organizing institutions, the assembled public was neither long lasting nor diverse. Most of the participants were people who were already part of the hacker or maker community. Only a few citizens stayed until the end and got through the hacking process. Also, as of now, the groups no longer work together. Thus, the hackathon did not achieve its original objective to create sustainable solutions for the city. Instead, it created an awareness for civic problems in another way - that is, through creating prototypes. Therefore, we assume that civic hackathons like this generate a temporally limited, unstable but affected public. This public is still exclusive and consists of participants with and without expertise in the field of hacking and making - but all of them gain and produce technoscientific knowledge while working on their prototypical innovations. The societal impact of this knowledge production should, however, not be overestimated because it is limited by the specific social, spatial and temporal elements of the format. Yet, a central discursive function of the event was the communication of technoscience: It positioned socio-technical innovations as possible solutions for urban problems.

\section{Discussion}

Our case studies reveal that civic technoscience is performed in heterogeneous ways. The three cases differ substantially in terms of governance mechanisms, dynamics of inclusion and exclusion, spatialities and temporalities and the (blurring of) boundaries between experts and laypersons.

\section{Governance mechanisms:}

The FabLab as well as the entrepreneurial makerspace are both membership-based formal organizations, but very different ones: The FabLab was established bottom-up, through citizens inspired by ideas of hacking and making, whereas the makerspace is rooted in the innovation strategies of industrial and academic organizations. The FabLab is a club, collectively governed by its members. The makerspace operates as a business with clear boundaries between employees (working for the organization) and users (paying membership fees). In all cases (including the hack- 
athon), formal organizations provide platforms for projects developed by persons outside the respective organizations. Hence, the success of all of these different institutionalizations of civic technoscience depends on the attraction of committed publics. This became especially apparent in the case of the hackathon, because it needed to assemble a crowd capable of developing prototypes in a very short timeframe. The main governance challenge of such a format is to give participants freedom to experiment while keeping the event at the same time structured and focused.

\section{Dynamics of inclusion and exclusion}

All three cases are shaped by a discourse of universal inclusion: Everyone is invited, anyone can participate. The public constructed by invitations, public statements and promotional materials was therefore a very general one. Moreover, the events and spaces were designed as open platforms. Our ethnographic observations, however, revealed more complex dynamics of inclusion and exclusion. In none of the cases were groups of people explicitly excluded. The exclusion was rather implicitly inscribed into the infrastructures and organizational formats. In each case, an already existing technical expertise allowed participants to integrate themselves into civic technoscience and to contribute to the development of ideas and projects. The investigated makerspace was the most exclusive instance of civic technoscience, while the FabLab - corresponding with its strong focus on education - proved to be the most inclusive one.

\section{Spatialities and temporalities}

Participation in civic technoscience takes place at specific places. In all three cases, these places were designed as workshops, equipped with tools for collaborating, hacking and making. These workshops were more or less professional, ranging from just a few tools in the case of the hackathon to a very expensive infrastructure, which fulfils industrial standards in the case of the investigated makerspace. The respective infrastructure has a strong influence on the practices and constitutions of publics as well as on the governance of the organizations. In all cases, the local workshops were entangled with larger networks (e.g., open source and maker communities), positioning the specific places as nodes and instances of a 'movement' of civic technoscience. Even the hackathon had long-term aspirations as the prototypes were originally imagined to be further developed in 'Citizen Science Labs'. It became clear that an ongoing commitment of participants as well as stable financial resources are crucial factors for the sustainability of civic technoscience.

\section{(Blurring of) boundaries between experts and laypersons.}

Citizen science discourses often imply a blurring of boundaries between experts and lay persons. Expertise should be reconfigured and redistributed by novel forms of public participation based on open digital and material infrastructures. In all our investigated instances of civic technoscience, we could observe a sharing and pooling of technoscientific expertise. All cases comprised of educational elements in which experts translate technoscientific knowledge to an assembled public. This also reveals that the distinction of experts and laypersons does not vanish in civic technoscience. However, the communication structures did not conform to the 'deficit model', because in all cases the assembled publics were either addressed as experts for specific issues or addressed as laypersons which might become experts by taking part in civic technoscience. In fact, we could observe participants who became experts in specific areas by participating in civic technoscience. The limits of a diffusion of expertise rests in the implicit exclusion mechanisms in all three cases. We conclude that a pre-existing technical familiarity, including cultural and habitual aspects, is an important factor for participation in civic technoscience. It increases the chances for people to participate in the first place and to participate in a substantial manner.

\section{Conclusion: Civic technoscience between emancipation, entrepreneurship and science communication}

Just as citizen science aims to open and extend the scientific enterprise to the public, civic tech- 
noscience aims to open and extend the technoscientific enterprise. And just as technoscience is shaped by imaginaries of future technologies, civic technoscience is shaped by the imaginary of a democratization of engineering and design. Hence, a discourse of inclusion and extension is very visible in all three cases: The workshops invited a general and unspecified public to participate. They all expressed the ideal of a technological culture in which everyone can and should take part in designing our world by means of tinkering, hacking, making and engineering. Our case studies show, however, that these aspirations of universal inclusion are limited by the design of the respective participatory formats as well as by the expertise of the participants.

Civic technoscience as a situated practice might not fulfil the utopian expectations of 'making' and 'hacking' as technosocial imaginaries. It does, however, imply an opening of specific technological black boxes. Civic technoscience makes practices of hacking, tinkering, making and engineering (more) public - be it in the service of political, economic or educational goals. To this end, new infrastructures (like makerspaces), technologies (like 3D printers) and events (like hackathons) are constructed. Thus, the publics of civic technoscience are themselves engineered by socio-technical means: They are assembled as parts of the contemporary technoscientific regime - as transformative parts that should make this regime more open, inclusive and/or innovative. Such transformative efforts, however, are launched by different actors that are differently positioned within the regime, resulting in different ambitions and practices of transformation, some of which tend to reproduce existing closures.

- The grassroots FabLab follows an emancipatory approach to civic technoscience. It assembles heterogeneous publics in which digital networks are entangled with localized practices. The FabLab itself is created as a tool for empowerment and public education. It is designed as a civil society organization that aspires to make digital fabrication public. This is also reflected in the bottom-up governance structure and an explicit reflection and problematization of the distinction between experts and laypersons.
- The entrepreneurial makerspace follows an entrepreneurial approach. The makerspace takes the form of an enterprise focused on fostering innovation. In this case, making technology and knowledge production public is not primarily a political aim but a business model. Despite its self-description as being open for everybody, the public of the makerspace is much more exclusive, consisting primarily of professional engineers and start-ups who use the infrastructure of the workshop. The makerspace offers them the opportunity to use rapid prototyping machines and to collaborate outside of the confinements of their organizations.

- The civic hackathon represents a science communication approach to civic technoscience. The hackathon is part of a governmental science policy and public relations strategy. Its aim was to develop prototypes for urban innovation. While the hackathon was not successful in generating a diverse and long-lasting public, the exercise in public prototyping produced an increased public familiarity with specific technologies and promoted public prototyping as a tool for addressing societal and sustainability problems. Furthermore, it endorsed the idea that public problems can be solved by means of technoscience as a public activity.

In the three approaches, civic technoscience "question[s] the state of things" (Wylie et al. 2014, 118) quite differently. In the entrepreneurial mode, dominant production and innovation regimes are problematized. In the science communication mode, local and global societal problems are addressed by technological means. In the emancipatory mode, the problematization extends to overarching political issues and social structures.

Our ethnographic research revealed that the three modes need to be considered as ideal types. We propose that civic technoscience is typically shaped by an entanglement of emancipatory, entrepreneurial and science communication aspirations and practices: Instead of sharp separations between these modes, we could observe nuanced differences in our cases. While the FabLab positions itself as a civil society organization, it 
also functions as an incubator for entrepreneurial ideas. It likewise engages in the communication of technoscience by educating publics about novel technologies. At a first glance, the entrepreneurial makerspace might be considered purely as business (and maybe not as an instance of civic technoscience at all). However, its very business model depends on the assemblage of publics interested in using and developing technologies. The discourse of "democratizing innovation" (Hippel, 2005) is not just 'talk'. It is constitutive for the self-understanding of the organization. Moreover, its communication strategies rest on the notion that (digital) fabrication technologies become accessible for the public. Hence, it also engages in the communication of technoscientific possibilities. The hackathon worked primarily as a science communication exercise. However, its promise of generating innovation through an emancipatory bottom-up approach was constitutive in attracting a public in the first place.

In all these cases, publics are not restricted to the role of consumers who buy and apply technologies. They are also are not positioned as entities that just need to be informed about technoscientific knowledge (the public understanding of science paradigm) or addressed as a variety of stakeholders that participate in critical discourses and deliberations (the public engagement paradigm). Rather, in civic technoscience, heterogeneous publics revolve around the co-production of artefacts. Whereas citizen science questions the jurisdictional claim of professional science over the production of facts, civic technoscience (in all three cases) questions the jurisdic- tional claim of professional engineering over the production of technological artefacts. It is a mode of knowledge production as well as a tool to increase technoscientific literacy. Publics in civic technoscience are not primarily formed to address technoscientific problems but to create new technoscientific solutions (for problems created or not created by technoscience). They are assembled as "performing audiences" (Andersen and Knudsen, 2016: 448), which themselves take part in the invention and production of technologies as well as new techno-social worlds.

Civic technoscience does not only imply a gathering of publics engaged in engineering. Civic technoscience needs to be also understood as an engineering of such publics themselves. It is realized by a socio-technical assembling of citizens, which are expected to perform (more or less specific) functions. Our cases demonstrate that this engineering of publics does not produce a general democratization of engineering and design. Rather, it produces situated publics of both certified and non-certified experts in different social contexts and settings that openly experiment with technologies. From the organizers' position, the specific settings and events of civic technoscience are themselves conceived as prototypes of participatory machines. The organizers act as 'social engineers' who aspire to learn from these prototypes - in order to build new upgrades and updates for FabLabs, makerspaces and hackathons. It is not by realizing utopian imaginaries but by creating prototypes for engineering publics that civic technoscience expands the regime of technoscience into society. 


\section{References}

Abbott A (2007) The System of Professions: An Essay on the Division of Expert Labor. Chicago: University of Chicago Press.

Andersen NA and Knudsen $\mathrm{H}$ (2016) Playful hyper-responsibility and the making of a performing audience. Soziale Systeme 19(2): 433-455.

Bonney R, Cooper CB, Dickinson J, Kelling S, Phillips T, Rosenberg KV and Shirk J (2009) Citizen Science: A Developing Tool for Expanding Science Knowledge and Scientific Literacy. BioScience 59(11): 977-984.

Bonney R, Phillips TB, Ballard HD and Enck JW (2016) Can Citizen Science Enhance Public Understanding of Science? Public Understanding of Science 25(1): 2-16.

Castells M (2002) The Internet galaxy: reflections on the Internet, Business, and Society. Oxford: Oxford University Press.

Collins H and Evans R (2002) The Third Wave of Science Studies: Studies of Expertise and Experience. Social Studies of Science 32(2): 235-296.

Dickel S and Franzen M (2016) The "Problem of Extension" Revisited: New Modes of Digital Participation in Science. Journal of Science Communication 15(1): 1-17.

Dickel S and Schrape JF (2017) The renaissance of techno-utopianism as a challenge for responsible innovation. Journal of responsible Innovation 19(2): 1-6.

Fablabs.io (2018) Labs. Available at: https://www.fablabs.io/labs (accessed 13.9.2018).

Finke P (2014) Citizen Science: Das unterschätzte Wissen der Laien. München: Oekom.

Gaskell G, Eyck TT, Jackson J and Veltri G (2005) Imagining Nanotechnology: Cultural Support for Technological Innovation in Europe and the United States. Public Understanding of Science 14(1): 81-90.

Gershenfeld NA (2012) How to Make Almost Anything: The Digital Fabrication Revolution. Foreign Affairs 91(6): 43-57.

Grunwald A (2014) The Hermeneutic Side of Responsible Research and Innovation. Journal of Responsible Innovation 1(3): 274-291.

Hippel E (2005) Democratizing Innovation. Cambridge, MA: MIT Press.

Jalbert, K (2016) Building Knowledge Infrastructures for Empowerment: A Study of Grassroots Water Monitoring Networks in the Marcellus Shale. Science \& Technology Studies 29(2): 26-43

Jasanoff S (2003) Technologies of Humility: Citizen Participation in Governing Science. Minerva 41(3): 223-244.

Jasanoff S and Kim S-H (2009) Containing the Atom: Sociotechnical Imaginaries and Nuclear Power in the United States and South Korea. Minerva 47(2): 119-146.

Knorr-Cetina K (1997) Sociality with Objects: Social Relations in Postsocial Knowledge Societies. Theory, Culture \& Society 14(4): 130.

Latour B (1987) Science in Action: How to Follow Scientists and Engineers Through Society. Cambridge, MA: Harvard University Press.

Latour B (1993) We Have Never Been Modern. Cambridge, MA: Harvard University Press.

Lösch A and Schneider C (2016) Transforming Power/Knowledge Apparatuses: The Smart Grid in the German Energy Transition. Innovation: The European Journal of Social Science Research 29(3): 262-284.

Marres N (2012) Material Participation: Technology, the Environment and Everyday Publics. Houndmills, Basingstoke, Hampshire, New York: Palgrave Macmillan. 
Mumford L (1970) The Myth of the Machine. New York: Harcourt Brace Jovanovich.

Nordmann A (2011) The Age of Technoscience. In: Nordmann A, Radder H and Schiemann G (eds) Science Transformed? Debating Claims of an Epochal Break. Pittsburgh, PA: University of Pittsburgh Press, pp. 19-30.

Nordmann A (2016) Enhancing Machine Nature. In: Hurlbut JB and Tirosh-Samuelson H (eds) Perfecting Human Futures. Wiesbaden: Springer, pp. 195-214.

Nordmann A and Schwarz A (2010) Lure of the 'Yes': the Seductive Power of Technoscience. In: Kaiser M, Kurath M, Maasen S and Rehmann-Sutter C (eds) Governing Future Technologies: Nanotechnology and the Rise of an Assessment Regime. Dordrecht, New York: Springer, pp. 255-277.

Roco MC and Bainbridge WS (2003) Converging Technologies for Improving Human Performance: Nanotechnology, Biotechnology, Information Technology and Cognitive Science. Dordrecht: Kluwer.

Sand M and Schneider C (2017) Visioneering Socio-Technical Innovations - A Missing Piece in the Puzzle. Nano Ethics 11(1): 19-29.

Schneider C (2018) Opening digital fabrication: transforming TechKnowledgies. Karlsruhe: KIT Scientific Publishing.

Schrock AR (2016) Civic hacking as data activism and advocacy. A history from publicity to open government data. New Media \& Society 18: 581599.

Serrano Sanz F, Holocher-Ertl T, Kieslinger B, Sanz Garcia F and Silva CG (2014) White Paper on Citizen Science for Europe. Unpublished manuscript.

Tkacz N (2015) Wikipedia and the politics of openness. Chicago; London: University of Chicago Press.

Troxler P (2014) Fab Labs Forked: A Grassroots Insurgency inside the Next Industrial Revolution. Journal of Peer Production 5.

Urry J (2016) What is the future? Cambridge, UK; Malden, MA: Polity Press.

Wylie S, Jalbert K, Dosemagen S and Ratto M (2014) Institutions for Civic Technoscience. How Critical Making is Transforming Environmental Research. The Information Society 30 (2): 116-126. 